\title{
Knowledge, Attitude and Practice of Standard Precautions amongst Allied Oral Healthcare Personnel In Lagos State
}

\author{
Moyosoore Osoba ${ }^{1 *}$, Olufemi Olulaja ${ }^{1}$, Oluwafemi Oyadiran ${ }^{2}$, Omotoye Itunuola ${ }^{3}$, \\ Oluwatoyosi Afolabi ${ }^{4}$, Abode Emilomo ${ }^{3}$ and Afolabi Oyapero ${ }^{3}$
}

${ }^{1}$ African Centre of Excellence for Genomics of Infectious Diseases, Nigeria

${ }^{2}$ Medical Research Council Unit The Gambia, London School of Hygiene and Tropical Medicine, Fajara, The Gambia

${ }^{3}$ Lagos State University College of Medicine, Lagos, Nigeria

${ }^{4}$ Heartland Alliance LTD/GTE, Lagos, Nigeria

\begin{abstract}
Background: Allied oral healthcare practitioners such as dental technologists, dental therapists, dental technicians, dental nurses etc., are invariably exposed to patients' blood or/and body fluids and this poses a health risk to oral healthcare workers and patients. This study aimed to assess the knowledge, attitude and practices of standard precautions (SP) amongst allied oral healthcare workers in Lagos State.
\end{abstract}

Methods: This study was a cross-sectional study which entailed the distribution of structured, self-administered questionnaires to a consecutively recruited convenience sample of 113 allied oral healthcare practitioners in both private and public oral healthcare facilities in Lagos State. Data entry and analysis was done using SPSS. Bivariate analysis was done to determine association between variables. $\mathrm{P}<0.005$ was considered significant.

Results: Most (85\%) of respondents displayed good overall knowledge of standard precautions. Majority (77\%) of respondents had a positive attitude towards standard precautions. Overall practice of standard precautions amongst the participants in the study was good (92\%). However, most (74.3\%) of the respondents exhibited moderate correctness in the practice of standard precautions, while few (14.2\%) demonstrated a high level of correctness; those with poor level of overall correctness in the practice of standard precautions were the least (11.5\%). Factors chiefly associated with low or no compliance with standard precautions were lack/inadequate provision of personal protective equipment (85\%), inadequate awareness on need for standard precautions (72.6\%), stress associated with compliance (67.3\%), and lack of basic amenities e.g. soap, water (64.6\%).

Conclusion: The study showed that the knowledge, attitude and practice of standard precautions among allied oral healthcare workers in both private and public healthcare facilities was fair as majority had good knowledge, attitude and practice of standard precautions. However, there is an urgent need to address the issues with reference to the barriers to compliance with standard precautions identified in the study.

\section{Keywords}

Allied oral healthcare practitioners, Standard precautions, Infectious diseases

\section{Introduction}

In oral healthcare service delivery, the dentist is principally responsible for diagnosing and treating dental patients; allied dental personnel are other members of the team who provide support to the dentist in the administration of oral healthcare [1]. Allied dental professionals include dental technologists, dental technicians, dental therapists, dental nurses, dental hygienists, dental assistants etc [2]. Oftentimes, the dentist delegates certain tasks to the allied dental personnel pertaining to the delivery of oral health
*Corresponding author: Moyosoore Osoba, African Centre of Excellence for Genomics of Infectious Diseases, Federal Medical Centre Owo, Nigeria, Tel: 07084156779

Accepted: December 23, 2021

Published online: December 27, 2021

Citation: Osoba M, Olulaja O, Oyadiran O, et al. (2021) Knowledge, Attitude and Practice of Standard Precautions amongst Allied Oral Healthcare Personnel In Lagos State. J Oral Healthc 2(1):20-28 
care [3]. The functions, duties and roles of the allied dental personnel are regulated in accordance with the legislation of the country and/or local regulations where they are found ${ }^{1}$. In most jurisdictions, allied dental personnel perform basic preventive and restorative dental services, thereby allowing dentists concentrate on more complex oral health service delivery [4].

Generally, health care workers are at risk of infection with bloodborne pathogens such as hepatitis B virus, human immunodeficiency virus, and hepatitis C virus etc [5]. Dentistry is a high-risk profession with respect to occupationallyacquired infectious diseases as it mostly involves a surgical field with frequent exposure to blood and body fluids of patients [6]. Dental professionals are particularly predisposed to occupational hazards such as exposure to infections, percutaneous exposure incidents, dental materials, respiratory disorders, eye insults etc [7]. As a result, oral health care workers, through occupational exposure, may have a 10 times greater risk of becoming a chronic hepatitis $B$ carrier than the average citizen [5]. It is therefore pertinent that strict infection prevention and control measures are instituted and adhered to in any dental facility to protect both patients and oral healthcare workers [8].

Standard Precautions are the basic level of infection control precautions which are to be used, as a minimum, in the care of all patients [9]. Standard Precautions are used to prevent transmission of diseases that can be acquired by contact with blood, body fluids, non-intact skin (including rashes), and mucous membranes [10]. They are meant to reduce the risk of transmission of pathogens from dental healthcare personnel to patients; from patients to dental healthcare personnel; and from one dental healthcare personnel to another [11]. Standard Precautions were introduced in 1996 by the Centre for Disease Control (CDC) as a set of infection control measures applicable when contacting all patients [12]. Components of Standard Precautions include the use of protective attire and barrier techniques (Personal Protective Equipment) such as gloves, surgical masks, face shields, aprons and reusable or disposable gowns; handwashing and care of hands; use and care of sharp instruments and needles (including Sharps Injury Management) and; appropriate healthcare waste management [13].

The attitude to, and practice of standard precautions amongst allied dental personnel will stem from their knowledge and understanding of the importance of standard precautions. This study will focus on assessing the knowledge of infection control amongst allied dental personnel, and how the knowledge has influenced their attitude and practice of standard precautions. An assessment of the knowledge, attitude and practice of standard precautions by healthcare workers is a prerequisite for initiating and implementing a successful infection prevention and control strategy in any health facility [14].

\section{Methods}

\section{Study location}

This study was carried out in various healthcare facilities in Lagos State. Lagos State is one of the thirty-six States in
Nigeria located in the Southwestern geopolitical area of the country. Though the smallest state in Nigeria in terms of land mass, Lagos is the most populous city in Nigeria! [15] It is therefore unsurprising to find that Lagos is amongst the States with the highest number of oral healthcare facilities in the country [16]. This is a cross sectional, descriptive study amongst allied oral health personnel in both public and private dental facilities in Lagos State.

\section{Ethical considerations}

Approval for the study was sought and obtained from the Department of Research and Ethical Committee, Lagos State University Teaching Hospital (LASUTH), Ikeja, Lagos (LREC. 06/10/1061). Participation in the study was voluntary; participants were informed that they could refuse to enlist in the study. A written informed consent was obtained from respondents.

\section{Sample selection}

A convenience sampling technique was used to determine the respondents in this study. Allied oral health practitioners were consecutively recruited from private and public dental clinics in Lagos. The two teaching hospitals in Lagos were used; five private hospitals and five general hospitals were selected conveniently across the five divisions of Lagos state based on the availability of dental clinics in each division.

Those included in the study were allied oral healthcare personnel who had been in practice for at least one year. Those excluded were allied oral healthcare personnel not willing to partake in the study.

\section{Data collection and data collection tool}

Data collection in this study was via self-administered questionnaires. This was because allied oral healthcare personnel had attained tertiary education and hence, were expected to be able to read and write, as well as being conversant with the concept of 'standard precautions'. Using Fischer's formula $n=Z^{2} p q / d^{2}$, a sample size of 102 was determined. The sample size was increased to 113 to make provision for $10 \%$ attrition. The questionnaire was divided into six sections which obtained information on sociodemography; knowledge of standard precautions; attitude to standard precautions; practice of standard precautions; correctness of the practice of standard precautions; and factors associated with low or non-compliance with standard precautions.

\section{Data analysis}

The questionnaires were manually checked for errors before entry into the computer. The data was analyzed using Statistical Package for Social Sciences (SPSS) version 21 and Microsoft Excel. The data was presented using frequency tables and charts Tests of significance were performed using a $95 \%$ confidence interval, and the level of significance was set at $P=0.005$. Bivariate analysis was done to determine associations between variables. 
Citation: Osoba M, Olulaja O, Oyadiran O, et al. (2021) Knowledge, Attitude and Practice of Standard Precautions amongst Allied Oral Healthcare Personnel In Lagos State. J Oral Healthc 2(1):20-28

\section{Results}

Most respondents were in the age category of $30-39$ years (62.8\%); married (57.5\%); and they were mostly Higher National Diploma holders (79.6\%). Majority were dental nurses $(46.9 \%)$, most respondents were from the Yoruba tribe $(85.8 \%)$, and a significant number $(66.4 \%)$ had less than 5 years working experience (Table 1$)$.

All $113(100.0 \%)$ respondents had heard of standard precautions and they all knew that the importance of standard precautions is to prevent the spread of disease. Table 2 shows that most of the respondents knew the diseases that could be spread by not following standard precautions which were hepatitis (83.2\%); HIV (69.9\%); Tuberculosis (60.2\%); Tetanus (54\%). Few of the respondents felt that 'Cancer' could be spread by not following standard precautions (23.9\%). The respondents displayed a good knowledge of the components of standard precautions to be: use of personal protective equipment (PPE 100.0\%), proper disposal of sharps (100.0\%) and sterilization of dental instrument (100.0\%), hand washing (91.2\%), and appropriate waste management (89.4\%). Most respondents (96.5\%) felt that standard precautions should be employed for 'all patients'.
The major situations that put patients at risk of hospitalacquired infection through health workers were determined to be 'not wearing gloves during patients handling (46.9\%)' and 'not wearing gloves during handling of instruments $(44.2 \%)$ '. The respondents showed good knowledge of the moments when hand washing was most important with an average score of $74.4 \%$. Most respondents submitted that facemasks should be worn mainly when aerosols are generated from dental procedure (92.0\%).

Table 3 shows that majority of the respondents agreed (86.7) that standard precautions were essential but majority of the respondents disagreed (61.9\%) that precautions should be followed for high risk patients only; instead, standard precautions should be followed for all patients (98.2\% respondents). Most of the respondents disagreed $(40.7 \%)$ that the guidelines for standard precautions were not really clear. Majority of the respondents (49.6\%) disagreed that wearing of gloves was more important than using of facemasks in preventing infection and most of the respondents disagreed (50.4\%) to feeling uncomfortable reminding a senior colleague to follow standard precautions. Majority of the respondents (68.1\%) agreed that there were

Table 1: Socio-demographics characteristics of respondents.

\begin{tabular}{|c|c|c|}
\hline Variable & Frequency $(n=113)$ & Percentage \\
\hline \multicolumn{3}{|l|}{ Age group (Years) } \\
\hline $20-29$ & 29 & 25.7 \\
\hline $30-39$ & 71 & 62.8 \\
\hline$\geq 40$ & 13 & 11.5 \\
\hline \multicolumn{3}{|l|}{ Marital status } \\
\hline Single & 48 & 42.5 \\
\hline Married & 65 & 57.5 \\
\hline \multicolumn{3}{|l|}{ Highest educational level } \\
\hline Ordinary National Diploma (OND) & 17 & 15.0 \\
\hline Higher National Diploma (HND) & 90 & 79.6 \\
\hline Bachelor of Science (BSc) & 4 & 3.5 \\
\hline Postgraduate (PG) & 2 & 1.8 \\
\hline \multicolumn{3}{|l|}{ Job type } \\
\hline Dental technologist & 43 & 38.1 \\
\hline Dental nurse & 53 & 46.9 \\
\hline Dental therapist & 13 & 11.5 \\
\hline Dental surgical assistant & 4 & 3.5 \\
\hline \multicolumn{3}{|l|}{ Religion } \\
\hline Islam & 39 & 34.5 \\
\hline Christianity & 74 & 65.5 \\
\hline \multicolumn{3}{|l|}{ Ethnic group } \\
\hline Yoruba & 97 & 85.8 \\
\hline Igbo & 11 & 9.7 \\
\hline Others & 5 & 4.4 \\
\hline \multicolumn{3}{|l|}{ Length of service (Years) } \\
\hline$\leq 5$ & 75 & 66.4 \\
\hline$>5$ & 38 & 33.6 \\
\hline \multicolumn{3}{|l|}{ Hospital category } \\
\hline Public & 82 & 72.6 \\
\hline Private & 31 & 27.4 \\
\hline
\end{tabular}


Citation: Osoba M, Olulaja O, Oyadiran O, et al. (2021) Knowledge, Attitude and Practice of Standard Precautions amongst Allied Oral Healthcare Personnel In Lagos State. J Oral Healthc 2(1):20-28

Table 2: Knowledge of standard precautions.

\begin{tabular}{|c|c|c|}
\hline Variable & Frequency $(n=113)$ & Percentage \\
\hline \multicolumn{3}{|l|}{${ }^{*}$ Disease likely to be contracted by not following SP } \\
\hline Hepatitis & 94 & 83.2 \\
\hline Tuberculosis & 68 & 60.2 \\
\hline Cancer & 27 & 23.9 \\
\hline Tetanus & 61 & 54.0 \\
\hline HIV/AIDS & 79 & 69.9 \\
\hline \multicolumn{3}{|l|}{${ }^{*}$ Components of SP } \\
\hline Use of PPE & 113 & 100.0 \\
\hline Hand washing & 103 & 91.2 \\
\hline Proper disposal of sharps & 113 & 100.0 \\
\hline Appropriate waste management & 101 & 89.4 \\
\hline Sterilization of dental instrument & 113 & 100.0 \\
\hline \multicolumn{3}{|l|}{ *When SP should be employed } \\
\hline Only for suspected high risk patients & 44 & 38.9 \\
\hline For all patients & 109 & 96.5 \\
\hline For no patients & 28 & 24.8 \\
\hline After diagnostic test are run on patients & 50 & 44.2 \\
\hline \multicolumn{3}{|c|}{ "Situation that put patients at risk of hospital acquired infection through health worker } \\
\hline Not wearing gloves during patients handling & 53 & 46.9 \\
\hline Not wearing gloves during handling of instrument & 50 & 44.2 \\
\hline Handshake with relatives & 10 & 8.8 \\
\hline Artificial fingernails & 0 & 0 \\
\hline \multicolumn{3}{|l|}{${ }^{*}$ Critical moments hand washing is important } \\
\hline Before touching patients & 95 & 84.1 \\
\hline In between patients & 62 & 54.9 \\
\hline After physical contact with patients & 93 & 82.3 \\
\hline Immediately after a risk of body fluid exposure & 96 & 85.0 \\
\hline After exposure to the immediate surroundings of a patient & 88 & 77.9 \\
\hline Immediately before an aseptic procedure & 80 & 70.8 \\
\hline After inserting an invasive device & 75 & 66.4 \\
\hline \multicolumn{3}{|l|}{${ }^{*}$ Facemask should be worn for the following reasons } \\
\hline When patients have bad breath/ halitosis & 93 & 82.3 \\
\hline When aerosols are generated from dental procedure & 104 & 92.0 \\
\hline When it is ascertained that patient has transmittable ID & 94 & 83.2 \\
\hline All times there is contact with patients or its body fluids & 97 & 85.8 \\
\hline
\end{tabular}

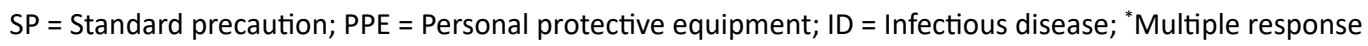

Table 3: Attitude towards standard precaution.

\begin{tabular}{|c|c|c|c|}
\hline & Agree & Disagree & Indifferent \\
\hline Standard Precautions are essential & 98(86.7) & $1(0.9)$ & 14(12.4) \\
\hline Precautions should be followed for high risk patients only & $27(23.9)$ & 70(61.9) & $16(14.2)$ \\
\hline Standard precautions should be followed for all patients & $111(98.2)$ & $2(1.8)$ & $0(0.0)$ \\
\hline The guidelines are not really clear & $34(30.1)$ & $46(40.7)$ & $33(29.2)$ \\
\hline We do not have enough gloves and facemasks & $45(39.8)$ & $48(42.5)$ & 20(17.7) \\
\hline Wearing gloves is more important than using facemasks in infection prevention & $48(42.5)$ & $56(49.6)$ & $9(8.0)$ \\
\hline I would feel uncomfortable reminding a senior colleague to follow standard precautions & $41(36.3)$ & $57(50.4)$ & $15(13.3)$ \\
\hline There are not enough hand washing facilities in the clinic & 77(68.1) & $27(23.9)$ & $9(8.0)$ \\
\hline The skin of my hands becomes irritated when I wash my hands & $24(21.2)$ & $69(61.1)$ & 20(17.7) \\
\hline
\end{tabular}

not enough hand washing facilities in the clinic and $61.1 \%$ disagreed that the skin of their hands became irritated when they washed their hands.

Table 4 shows that most of the respondents (76.1\%) always washed their hands before touching a patient; more than half (51.8)\% always washed their hands in-between patients,
$84.1 \%$ always washed their hands after physical contact with patient, $92.9 \%$ of the respondents always washed their hands immediately after a risk of body fluid exposure. Majority of the respondents (85.8\%) always washed their hands immediately before an aseptic procedure and $85.8 \%$ of the respondents always washed their hands after inserting an invasive device. 
Citation: Osoba M, Olulaja O, Oyadiran O, et al. (2021) Knowledge, Attitude and Practice of Standard Precautions amongst Allied Oral Healthcare Personnel In Lagos State. J Oral Healthc 2(1):20-28

Table 4: Practice of standard precautions among respondents.

\begin{tabular}{|c|c|c|c|}
\hline & Always & Sometimes & Never \\
\hline Situation respondents wash hand: before touching a patient & $86(76.1)$ & $27(23.9)$ & $0(0.0)$ \\
\hline Situation respondents wash hand: In-between patients & $58(51.8)$ & 23(20.4) & $32(28.3)$ \\
\hline Situation respondents wash hand: after physical contact with patient & $95(84.1)$ & $14(12.4)$ & $4(3.5)$ \\
\hline Situation respondents wash hand: Immediately after a risk of body fluid exposure & 105(92.9) & $8(7.1)$ & $0(0.0)$ \\
\hline Situation respondents wash hand: after exposure to the immediate surroundings of a patient & $97(85.8)$ & $5(4.4)$ & 11(9.7) \\
\hline Situation respondents wash hand Immediately before an aseptic procedure & $94(83.2)$ & 19(16.8) & $0(0.0)$ \\
\hline Situation respondents wash hand: after inserting an invasive device & $97(85.8)$ & 16(14.2) & $0(0.0)$ \\
\hline Gloves wearing instances: Before touching a patient & $94(83.2)$ & 19(16.8) & $0(0.0)$ \\
\hline Gloves wearing instances: Before touching hand instruments & $81(71.7)$ & $32(28.3)$ & $0(0.0)$ \\
\hline Gloves wearing instances: While handling patients' impression & $98(86.7)$ & $15(13.3)$ & $0(0.0)$ \\
\hline Gloves wearing instances: While performing scaling \& polishing & $98(86.7)$ & $9(8.0)$ & $6(5.3)$ \\
\hline Gloves wearing instances: While handling patients' denture & $91(80.5)$ & 22(19.5) & $0(0.0)$ \\
\hline Facemask wearing instances: When assisting a Dentist working on a patient & $90(79.6)$ & 21(18.6) & $2(1.8)$ \\
\hline Facemask wearing instances: When performing scaling \& polishing & $97(85.8)$ & $16(14.2)$ & $0(0.0)$ \\
\hline Facemask wearing instances: When trimming dentures & $93(82.3)$ & $15(13.3)$ & $5(4.4)$ \\
\hline Facemask wearing instances: When sterilizing instruments & $53(46.9)$ & $48(42.5)$ & 12(10.6) \\
\hline
\end{tabular}

Table 5: Correctness of practice of standard precautions..

\begin{tabular}{|c|c|c|}
\hline Variable & Frequency $(n=113)$ & Percentage \\
\hline \multicolumn{3}{|l|}{${ }^{*}$ How respondents wash hands } \\
\hline By rubbing hand palm to palm and rinsing in running water & 29 & 25.7 \\
\hline Rubbing hands palm to palm and in-between fingers and rinsing with soapy water in a basin & 14 & 12.4 \\
\hline $\begin{array}{l}\text { Rubbing hands palm to palm including in-between finger and fingertips and rinsing with a } \\
\text { soapy water in a basin }\end{array}$ & 21 & 18.6 \\
\hline $\begin{array}{l}\text { Rubbing hands palm to palm including in-between finger and fingertips and rinsing under } \\
\text { running water }\end{array}$ & 49 & 43.4 \\
\hline \multicolumn{3}{|l|}{ "The order of putting on PPE equipment } \\
\hline Apron/lab coat $\rightarrow$ facemask $\rightarrow$ gloves & 83 & 73.5 \\
\hline Gloves $\rightarrow$ Apron/lab coat $\rightarrow$ Facemask & 2 & 1.8 \\
\hline Facemask $\rightarrow$ Apron/Lab coat $\rightarrow$ Gloves & 28 & 24.8 \\
\hline \multicolumn{3}{|l|}{ *Hand instrument should be disinfected before sterilization } \\
\hline Always & 82 & 72.6 \\
\hline Sometimes & 31 & 27.4 \\
\hline \multicolumn{3}{|l|}{ "When disposing sharps needles should be removed from syringe before disposal } \\
\hline Yes & 97 & 85.6 \\
\hline No & 16 & 14.2 \\
\hline \multicolumn{3}{|l|}{ "When disposing sharps both needles and syringe should be disposed in the sharp box } \\
\hline Yes & 61 & 54.0 \\
\hline No & 52 & 46.0 \\
\hline \multicolumn{3}{|l|}{ "When recapping needles, Single hand technique should be used } \\
\hline Always & 63 & 55.8 \\
\hline Sometimes & 37 & 32.7 \\
\hline Never & 13 & 11.5 \\
\hline \multicolumn{3}{|l|}{${ }^{*}$ When recapping needles, double hand technique should be used } \\
\hline Always & 54 & 47.8 \\
\hline Sometimes & 23 & 20.4 \\
\hline Never & 36 & 31.9 \\
\hline
\end{tabular}

Majority of the respondents $(83.2 \%)$ always wore gloves before touching a patient; $71.7 \%$ before touching instruments; $86.7 \%$ while handling patients' impression; $86.7 \%$ while performing scaling and polishing; $80.5 \%$ while handling patients' denture.

Most (79.6\%) of the respondents always wore facemasks when assisting a dentist working on a patient; $85.8 \%$ when performing scaling and polishing; $82.3 \%$ when trimming dentures and $46.9 \%$ when sterilizing instruments.

Table 5 shows that majority $(43.4 \%)$ of the respondents washed their hands by rubbing hands palm to palm including in-between finger and fingertips and rinsing under running water (43.4\%); while most put on their personal protective equipment (PPE) in the order of Apron/lab coat $\rightarrow$ facemask $\rightarrow$ 
Citation: Osoba M, Olulaja O, Oyadiran O, et al. (2021) Knowledge, Attitude and Practice of Standard Precautions amongst Allied Oral Healthcare Personnel In Lagos State. J Oral Healthc 2(1):20-28

gloves (73.5\%). Also, it was seen that $72.6 \%$ of the respondents believed that hand instruments should always be disinfected before sterilization. When disposing sharps, $85.6 \%$ of the respondents affirmed that the needle should be removed from the syringe before disposal; $54 \%$ of the respondents felt that the needles and syringe should be disposed in the sharp box. When recapping needles, $55.8 \%$ respondents agreed that the single hand technique should always be used.

Table 6 shows that majority $(85.0 \%)$ of respondents attested to lack/inadequate provision of personal protective equipment as a factor associated with low or non-compliance with standard precaution, along with lack of basic amenities e.g soap, water (64.6\%); stress associated with compliance (67.3\%); inadequate awareness of need for standard precaution (72.6\%); excessive patients load (54.9\%); lack of role model among colleagues (57.5\%), and forgetfulness (51.3\%).

Table shows that lack or inadequate provision of personal protective equipment $(85.0 \%)$ is the major factor associated with low or non-compliance with standard precaution.

Table 7 shows that there exists a significant association between the socio-demographic characteristics and the knowledge of standard precautions. The age group $(\geq 40)$ had the highest percentage (100.0\%) of good knowledge of standard precautions. Married respondents had slightly better knowledge of standard precaution (86.2\%) as compared to single respondents (83.3); respondents who had Bachelor of Science and Postgraduate qualifications (100.0\%) had higher knowledge of standard precautions while dental surgical assistants had higher knowledge of standard precautions. Also those with years of experience $\leq 5$ had slightly higher knowledge of standard precaution (85.3\%) more than those with $>5$ years of experience (84.2\%).

Table 8 shows that there is a significant association between attitude toward precautions and socio-demographic characteristics. It was observed that the middle age group (30$39)$ positively had the highest percentage $(74.5 \%)$ of positive attitude towards standard precautions. Married respondents had better attitude towards standard precautions $(81.5 \%)$ as compared to single respondents $(70.8 \%)$; respondents who had Bachelor of science and Postgraduate qualifications (100.0\%) had a better attitude towards standard precautions while dental surgical assistants had better attitude (100\%) to standard precautions than other allied oral healthcare professionals. Respondents with years of experience $>5$ years had better attitude to standard precautions (84.2) than those with $\leq 5$ years of experience $(73.3 \%)$.
There is a significant correlation between overall practice of standard precautions and socio-demographic characteristics. Table 9 shows that respondents $\geq 40$ had the best $(100.0 \%)$ overall practice of standard precaution. Married respondents had a better overall practice of standard precaution (96.9\%) as compared to single respondents (85.4). Respondents who had a Bachelor of Science and Postgraduate qualifications $(100.0 \%)$ had better overall practice of standard precautions. Dental surgical assistants had better overall practice of standard precautions (100\%) than other job types. Respondents with years of experience $>5$ had slightly better overall practice $(92.1 \%)$ than those with $\leq 5$ years of experience (92\%).

\section{Discussion}

Overall, all respondents (100\%) showed knowledge of standard precautions with majority $(86.7 \%)$ agreeing that standard precautions were essential. This finding is consistent with evidence from other studies [17] but contrasts the findings of low level of knowledge of safety precautions among dental healthcare professionals in Shiraz, Iran [18]. The study found that about $76.1 \%$ and $84.1 \%$ of participants washed their hands before and after touching a patient, respectively, with about $83.4 \%$ putting on their gloves prior to contact with patients. This is encouraging as it shows that oral allied health workers put their knowledge to practice. The level of compliance seen in this study is consistent with other studies where dental practitioners put their knowledge to practice [19]. However, our finding contrasts the finding of low practice of standard precautions in Iran [18] and India [20]. Given the high likelihood of infection transmission in dentistry [5], the finding of high level of knowledge, positive attitude, and practice is encouraging as it showed that allied oral health workers have good knowledge of infection prevention and control.

Beyond the practice of safety precautions, this study explored the correctness of participants' practice. It is one thing to comply with standard precautions, it is another to comply correctly. For example, despite the encouraging level of compliance to hand washing, only about $43.4 \%$ practiced hand washing the correct way by rubbing hands palm to palm including in-between finger and fingertips and rinsing under running water. $73.5 \%$ of the allied oral health practitioners agree to donning their PPE in the correct sequence (apron facemasks - gloves). With infection prevention and control, it is important that standard precautions are carried out the

Table 6: Factors associated with low/non-compliance with standard precautions.

\begin{tabular}{|c|c|c|}
\hline Variables & Frequency $(n=113)$ & Percentage \\
\hline \multicolumn{3}{|l|}{ Factors associated with non-compliant with standard precautions } \\
\hline Lack/inadequate provision of PPE & 96 & 85.0 \\
\hline Stress associated with compliance & 76 & 67.3 \\
\hline Inadequate awareness on the need for standard precaution & 82 & 72.6 \\
\hline Excessive patients load & 62 & 54.9 \\
\hline Lack of role model among colleagues & 65 & 57.5 \\
\hline Forgetfulness & 58 & 51.3 \\
\hline
\end{tabular}


Citation: Osoba M, Olulaja O, Oyadiran O, et al. (2021) Knowledge, Attitude and Practice of Standard Precautions amongst Allied Oral Healthcare Personnel In Lagos State. J Oral Healthc 2(1):20-28

Table 7: Association between knowledge of standard precautions and socio-demographic characteristics.

\begin{tabular}{|c|c|c|c|c|c|}
\hline & Fair $(n=17)$ & Good $(n=96)$ & Total & $\mathbf{X}^{2}$ & $p$ - value \\
\hline \multicolumn{6}{|l|}{ Age group (Years) } \\
\hline $20-29$ & $10(34.5)$ & 19(65.5) & $29(100.0)$ & \multirow{3}{*}{$12.369^{* *}$} & \multirow{3}{*}{$0.002^{*}$} \\
\hline $30-39$ & $7(9.9)$ & $64(90.1)$ & $71(100.0)$ & & \\
\hline$\geq 40$ & $0(0.0)$ & $13(100.0)$ & $13(100.0)$ & & \\
\hline \multicolumn{6}{|l|}{ Marital status } \\
\hline Single & $8(16.7)$ & $40(83.3)$ & $48(100.0)$ & \multirow{2}{*}{0.172} & \multirow{2}{*}{0.678} \\
\hline Married & $9(13.8)$ & $56(86.2)$ & $65(100.0)$ & & \\
\hline \multicolumn{6}{|l|}{ Highest educational level } \\
\hline OND & $1(5.9)$ & $16(94.1)$ & $17(100.0)$ & \multirow{4}{*}{$2.705^{* *}$} & \multirow{4}{*}{0.439} \\
\hline HND & $16(17.8)$ & $74(82.2)$ & $90(100.0)$ & & \\
\hline BSC & $0(0.0)$ & $4(100.0)$ & $4(100.0)$ & & \\
\hline PG & $0(0.0)$ & $2(100.0)$ & $2(100.0)$ & & \\
\hline \multicolumn{6}{|l|}{ Job type } \\
\hline Dental technologist & $5(11.6)$ & $38(88.4)$ & $43(100.0)$ & \multirow{4}{*}{$1.708^{* *}$} & \multirow{4}{*}{0.635} \\
\hline Dental nurse & 10(18.9) & $43(84.6)$ & $53(100.0)$ & & \\
\hline Dental therapist & $2(15.4)$ & $11(84.6)$ & $13(100.0)$ & & \\
\hline Dental surgical assistant & $0(0.0)$ & $4(100.0)$ & $4(100.0)$ & & \\
\hline \multicolumn{6}{|l|}{ Length of service (Years) } \\
\hline$\leq 5$ & $11(14.7)$ & $64(85.3)$ & $75(100.0)$ & \multirow{2}{*}{0.025} & \multirow{2}{*}{0.875} \\
\hline$>5$ & $6(15.8)$ & $32(84.2)$ & $38(100.0)$ & & \\
\hline \multicolumn{6}{|l|}{ Hospital category } \\
\hline Public & $11(13.4)$ & $71(86.6)$ & $82(100.0)$ & \multirow{2}{*}{0.621} & \multirow{2}{*}{0.431} \\
\hline Private & $6(19.4)$ & $25(80.6)$ & $31(100.0)$ & & \\
\hline
\end{tabular}

${ }^{* *}$ Fisher exact test

Table 8: Association between attitude toward standard precautions and socio-demographic characteristics .

\begin{tabular}{|c|c|c|c|c|c|}
\hline & Negative $(n=26)$ & Positive $(n=87)$ & Total & $x^{2}$ & p-value \\
\hline \multicolumn{6}{|l|}{ Age group (Years) } \\
\hline $20-29$ & $7(24.1)$ & $22(75.9)$ & $29(100.0)$ & \multirow{3}{*}{$1.963^{* *}$} & \multirow{3}{*}{0.375} \\
\hline $30-39$ & $18(25.4)$ & $53(74.5)$ & $71(100.0)$ & & \\
\hline$\geq 40$ & $1(7.7)$ & $12(92.3)$ & $13(100.0)$ & & \\
\hline \multicolumn{6}{|l|}{ Marital status } \\
\hline Single & $14(29.2)$ & $34(70.8)$ & $48(100.0)$ & \multirow{2}{*}{1.786} & \multirow{2}{*}{0.181} \\
\hline Married & $12(18.5)$ & $53(81.5)$ & $65(100.0)$ & & \\
\hline \multicolumn{6}{|l|}{ Highest educational level } \\
\hline OND & $14(82.4)$ & $3(17.6)$ & $17(100.0)$ & \multirow{4}{*}{$40.345^{* *}$} & \multirow{4}{*}{$<0.001^{*}$} \\
\hline HND & $12(13.3)$ & $78(68.7)$ & $90(100.0)$ & & \\
\hline BSC & $0(0.0)$ & $4(100.0)$ & $4(100.0)$ & & \\
\hline PG & $0(0.0)$ & $2(100.0)$ & $2(100.0)$ & & \\
\hline \multicolumn{6}{|l|}{ Job type } \\
\hline Dental technologist & $10(23.3)$ & $33(76.7)$ & $43(100.0)$ & \multirow{4}{*}{$1.266^{* *}$} & \multirow{4}{*}{0.737} \\
\hline Dental nurse & $13(24.5)$ & $40(75.5)$ & $53(100.0)$ & & \\
\hline Dental therapist & $3(23.1)$ & 10(76.9) & $13(100.0)$ & & \\
\hline Dental surgical assistant & $0(0.0)$ & $4(100.0)$ & $4(100.0)$ & & \\
\hline \multicolumn{6}{|l|}{ Length of service (Years) } \\
\hline$\leq 5$ & $20(26.7)$ & $55(73.3)$ & $75(100.0)$ & \multirow{2}{*}{1.684} & \multirow{2}{*}{0.194} \\
\hline$>5$ & $6(15.8)$ & $32(84.2)$ & $38(100.0)$ & & \\
\hline \multicolumn{6}{|l|}{ Hospital category } \\
\hline Public & $21(25.6)$ & $61(74.4)$ & $82(100.0)$ & \multirow{2}{*}{1.141} & \multirow{2}{*}{0.285} \\
\hline Private & $5(16.1)$ & $26(83.9)$ & $31(100.0)$ & & \\
\hline
\end{tabular}

${ }^{* *}$ Fisher exact test 
Citation: Osoba M, Olulaja O, Oyadiran O, et al. (2021) Knowledge, Attitude and Practice of Standard Precautions amongst Allied Oral Healthcare Personnel In Lagos State. J Oral Healthc 2(1):20-28

Table 9: Association between overall practice of standard practice precautions and socio-demographic characteristics.

\begin{tabular}{|c|c|c|c|c|c|}
\hline & Fair $(n=9)$ & Good $(n=104)$ & Total & $f$ & p-value \\
\hline \multicolumn{6}{|l|}{ Age group (Years) } \\
\hline $20-29$ & $6(20.7)$ & $23(79.3)$ & $29(100.0)$ & \multirow{3}{*}{$8.885^{* *}$} & \multirow{3}{*}{$0.012^{*}$} \\
\hline 30-39 & $3(4.2)$ & $68(95.8)$ & $71(100.0)$ & & \\
\hline$\geq 40$ & $0(0.0)$ & $13(100.0)$ & $13(100.0)$ & & \\
\hline \multicolumn{6}{|l|}{ Marital status } \\
\hline Single & $7(14.6)$ & $41(85.4)$ & $48(100.0)$ & \multirow{2}{*}{4.987} & \multirow{2}{*}{$0.026^{*}$} \\
\hline Married & $2(3.1)$ & 63(96.9) & $65(100.0)$ & & \\
\hline \multicolumn{6}{|l|}{ Highest educational level } \\
\hline OND & $1(5.9)$ & $16(94.1)$ & $17(100.0)$ & \multirow{4}{*}{0.725} & \multirow{4}{*}{0.867} \\
\hline HND & $8(8.9)$ & $82(91.1)$ & $90(100.0)$ & & \\
\hline BSC & $0(0.0)$ & $4(100.0)$ & $4(100.0)$ & & \\
\hline PG & $0(0.0)$ & $4(100.0)$ & $2(100.0)$ & & \\
\hline \multicolumn{6}{|l|}{ Job type } \\
\hline Dental technologist & $5(11.6)$ & $38(88.4)$ & $43(100.0)$ & \multirow{4}{*}{1.519} & \multirow{4}{*}{0.678} \\
\hline Dental nurse & $3(5.7)$ & $50(94.3)$ & $53(100.0)$ & & \\
\hline Dental therapist & $1(7.7)$ & $12(92.3)$ & $13(100.0)$ & & \\
\hline Dental surgical assistant & $0(0.0)$ & $4(100.0)$ & $4(100.0)$ & & \\
\hline \multicolumn{6}{|l|}{ Length of service (Years) } \\
\hline$\leq 5$ & $6(8.0)$ & $68(92.0)$ & $75(100.0)$ & \multirow{2}{*}{0.000} & \multirow{2}{*}{0.984} \\
\hline$>5$ & $3(7.9)$ & $35(92.1)$ & $38(100.0)$ & & \\
\hline \multicolumn{6}{|l|}{ Hospital category } \\
\hline Public & $6(7.3)$ & $76(92.7)$ & $82(100.0)$ & \multirow{2}{*}{0.171} & \multirow{2}{*}{0.679} \\
\hline Private & $3(9.7)$ & $28(90.3)$ & $31(100.0)$ & & \\
\hline
\end{tabular}

"significant; ${ }^{* *} \mathrm{f}=$ fisher exact test.

right way. It is evident that regular trainings should be done on the correct way of undertaking standard precautions.

This study found several factors responsible for low level of compliance with safety precautions amongst allied oral healthcare workers. The most significant factor is lack/ insufficient personal protective equipment (PPE), others are stress associated with compliance, inadequate awareness of need for standard precautions, excessive patient load, lack of role models amongst colleagues, and forgetfulness. Our finding is consistent with similar studies from different populations in which same factors were implicated for poor compliance to standard precautions [21,22]. In addition to some of the factors explored in this study, unsupportive institutional culture has also been identified as a factor for poor compliance to standard precautions by allied oral health workers [21]. Most of these factors stress the need for a more proactive leadership of dental settings in order to achieve sufficient provision of PPE and establish supportive institutional culture with respect to compliance to standard precautions. Availability of PPE has been linked to increased compliance to standard precautions [23].

This study also established significant correlation between socio-demographic characteristics and knowledge, attitude, and practice of standard precautions amongst allied oral health workers. The level of academic qualification, years of dental practice and marital status have been found to have influence knowledge, attitude, and practice of standard precautions of allied dental practitioners. Overall, there is higher level of knowledge, positive attitude, and good practice of standard precautions amongst allied oral health workers who have bachelors or postgraduate degrees, the married, and those with $>5$ years experience in the dental field. This could be due to the fact those with longer years of practice have had or seen more cases of infection transmission and were therefore more cautious in preventing a recurrence. In a similar study of infection prevention, health workers with bachelor's degrees and higher were found to be two times more knowledgeable about infection prevention than their counterparts who had less than bachelor's degree [23].

\section{Conclusion}

The study showed that the knowledge, attitude and practice of standard precautions among allied oral healthcare workers in both private and public sector, was fair as majority of the health care workers had good knowledge, attitude and practice of standard precautions. However, there is an urgent requirement to address the issues with reference to the barriers to compliance with standard precautions identified in the study.

The findings in this study also buttress the fact that there is a need to restructure training programs to become more practical. Refresher training program for all categories of Healthcare workers should also be mandated. It should become a requirement for all Healthcare workers to attend the training programs at the time of their recruitment and it also should be prioritized in the curriculums of allied oral healthcare specialties. Decisiveness regarding the above will result in heightening the awareness, as well as improve the knowledge, attitude and practices of Standard Precautions amongst allied oral healthcare workers. 
Citation: Osoba M, Olulaja O, Oyadiran O, et al. (2021) Knowledge, Attitude and Practice of Standard Precautions amongst Allied Oral Healthcare Personnel In Lagos State. J Oral Healthc 2(1):20-28

\section{Acknowledgement}

We wish to acknowledge the department of dentistry at the Lagos state University Teaching Hospital for its support.

\section{References}

1. Brame Jennifer, Mitchell Shannon,Wilder Rebecca et al. (2015) Dental and allied dental students' attitudes towards and perceptions of intraprofessional education. Journal of dental education 79: 616-625.

2. Waldman H, Perlman Steven (2008) Allied dental personnel: Will there be enough? N Y State Dent J 74: 28-30.

3. Hach Maria, Aaberg KB, Lempert Susanne, et al. (2016) Work assignments, delegation of tasks and job satisfaction among Danish dental hygienists. Int J Dent Hyg 15: 229-235.

4. Purbay S, Kumari N, Tanwar AS, et al. (2019) Perception of dental professionals regarding integration of dental auxiliary into dental health delivery system. J Family Med Prim Care 8: 2720-2723.

5. Araujo Marcelo, Andreana Sebastiano (2002) Risk and prevention of transmission of infectious diseases in dentistry. Quintessence Int 33: 376-382.

6. Puttaiah Raghunath, Verma Mahesh, Patil Shankargouda, et al. (2010) The Influence of Infectious Diseases on Dentistry. World Journal of Dentistry 1: 225-231.

7. Ayatollahi J, Ayatollahi F, Ardekani AM, et al. (2012) Occupational hazards to dental staff. Dent Res J 9: 2-7.

8. Peter A Leggat, Ureporn Kedjarune, Derek R Smith (2007) Occupational Health Problems in Modern Dentistry: A Review. Ind Health 45: 611-621.

9. Ojulong J, Mitonga KH, lipinge SN (2013) Knowledge and attitudes of infection prevention and control among health sciences students at University of Namibia. Afr Health Sci 13: 1071-1078.

10. Murray J, Agreiter I, Orlando L, et al. (2018) BMT Settings, Infection and Infection Control. In: Kenyon M, Babic A, The European blood and marrow transplantation textbook for nurses: Under the Auspices of EBMT. Springer.

11. Volgenant CMC, de Soet JJ (2018) Cross-transmission in the Dental Office: Does This Make You III? Curr Oral Health Rep 5: 221-228.
12. Broussard IM, Kahwaji Cl (2020) Universal Precautions. StatPearls Publishing, Treasure Island, USA.

13. https://www.cdc.gov/oralhealth/infectioncontrol/summaryinfection-prevention-practices/standard-precautions.html

14. Ogoina D, Pondei K, Adetunji B, et al. (2015) Knowledge, attitude and practice of standard precautions of infection control by hospital workers in two tertiary hospitals in Nigeria. J Infect Prev 16: 16-22.

15. AA Rahman, A Barbieri, JC Fotso, et al. (2009) Urban populationenvironment dynamics in the developing world: Case studies and lessons learned. Committee for International Cooperation in National Research in Demography (CICRED), Paris.

16. Adeniyi Abiola, Sofola Oyinkansol, Kalliecharan Ricky (2012) An appraisal of the oral health system in Nigeria. Int Dent J 62: 292300.

17. EsamSalehHalboub, Sadeq Ali Al-Maweri, Aisha Ahmed AlJamaei, et al. (2015) J Int Oral Health 7: 15-19.

18. Askarian, M, Mirraei, K, Honarvar B, et al. (2005) Knowledge, attitude and practice towards droplet and airborne isolation precautions among dental health care professionals in Shiraz, Iran. J Public Health Dent 65: 43-47.

19. Haridi HK, Al-Ammar AS, Al-Mansour MI (2016) Compliance with infection control standard precautions guidelines: A survey among dental healthcare workers in Hail Region, Saudi Arabia. J Infect Prev 17: 268-276.

20. Singh A, Purohit BM, Bhambal A, et al. (2011) Knowledge, attitudes, and practice regarding infection control measures among dental students in Central India. J Dent Educ 75: 421427.

21. HamidrezaHedayati, Brahmaputra Marjadi, MehrdadAskarian (2014) Barriers to standard precautions adherence in a dental school in Iran: A qualitative study. AJIC 42: P750-P754.

22. Michael Christian, Emil NamakukaKikwilu (2014) Knowledge, attitude, reported behaviour and perceived challenges to adhering to infection control measures in dental practice among dental practitioners in Tanzania. Tanzania Dental Journal.

23. Desta M, Ayenew T, Sitotaw N, et al. (2018) Knowledge, practice and associated factors of infection prevention among healthcare workers in DebreMarkos referral hospital, Northwest Ethiopia. BMC Health Serv Res.

DOI: $10.36959 / 704 / 678$

Copyright: (c) 2021 Osoba M. This is an open-access article distributed under the terms of the Creative Commons Attribution License, which permits unrestricted use, distribution, and reproduction in any medium, provided the original author and source are credited. 